\title{
Factors Associated with Psychological Distress among Filipinos during Coronavirus Disease-19 Pandemic Crisis
}

\author{
Roy Rillera Marzo ${ }^{1 *}$, Emilio Quilatan Villanueva III ${ }^{2}$, Erwin Martinez Faller ${ }^{3}$, Aries Moralidad Baldonado ${ }^{4}$ \\ ${ }^{1}$ Department of Public Health, Faculty of Medicine, Asia Metropolitan University, Johor, Malaysia; ${ }^{2}$ Department of Pathology, College \\ of Medicine, University of the Philippines, Manila, Philippines; ${ }^{3}$ Department of Pharmacy, Faculty of Pharmacy, San Pedro College, \\ Davao City, Philippines; ${ }^{4}$ Department of Pharmacy, College of Nursing, Saint Alexius College, South Cotabato, Philippines
}

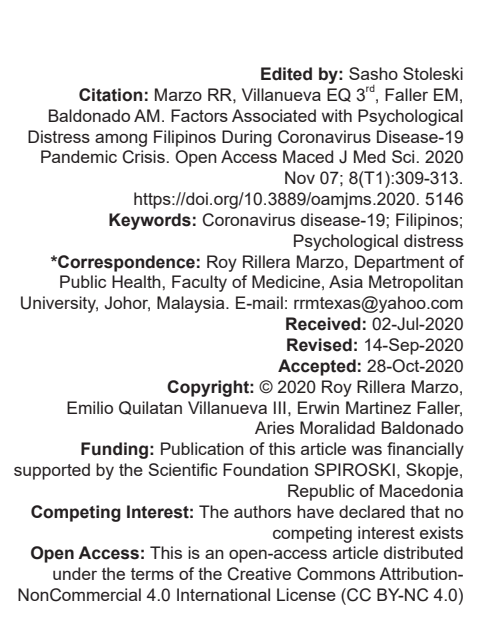

\section{Introduction}

Coronavirus (CoV) disease 2019 (COVID-19), referred to as severe acute respiratory syndrome CoV 2 (SARS-CoV-2), started in Wuhan, China, and has spread rapidly across the world [1], [2]. The disease was declared a Public Health Emergency of International Concern by the WHO on January 30, 2020. As of May 27,2020 , the global statistics of SARS-CoV-2 infections have included five million positive cases and 300,000 deaths; Southeast Asian Region with 218,523 positive cases reported with 6359 deaths. In the Philippines, there have been 15,049 positive cases and 904 reported deaths since May 28, 2020 [2].

The emergence of COVID-19 in Wuhan has created a confused and rapidly evolving situation. As expected, the UK media has reported a substantial psychological impact of both the outbreak and the response. Residents have been comparing the situation to the "end of the world." Hospitals have been "overwhelmed," and there have been concerns about food shortage. "Panic in Wuhan" is a common refrain [3].
The COVID-19 pandemic represents complex events, that is, complexities in its origin, spread, effects, and consequences at multiple levels and fields, including tourism [4], medical, social, political, economic, religious, cultural, and civilizational [5]. Unfortunately, the effects of CoV on mental health have not been extensively and systematically studied; nevertheless, the COVID-19 may have a rippling effect, particularly based on current public and political reactions [6].

Fear caused by COVID-19, severe clinic picture and deadliness, a strict quarantine, curfew and legal punishment, mistrust of officials who mismanaged the outbreak, and overflowing social media with misinterpretation and theories of conspiracy all have taken their toll on mental health [5], [7].

During an outbreak of an infectious disease, the psychological reactions of a population play a critical role in shaping both the spread of the disease and the occurrence of emotional distress and social disorder (even after the outbreak). However, sufficient resources are typically not provided to manage or attenuate the effects of a pandemic on mental health and well-being [8]. This might be understandable in the 
acute phase of an outbreak. When healthy systems prioritize testing, reducing transmission, and critical patient care, psychological and psychiatric needs should not be overlooked during any phase of pandemic management [8].

It is known that psychological factors play an important role in adherence to public health measures and how people cope with the threat of infection and consequent losses. Psychological reactions to pandemics include maladaptive behaviors, emotional distress, and defensive responses [8]. People at risk of psychological problems are vulnerable and may be affected by their mental health condition [8], [9], [10].

This study aims to identify the factors associated with psychological distress among Filipinos during the COVID-19 pandemic crisis. Furthermore, the prevalence and severity of psychological distress are measured and the current mental health burden is evaluated on society, which leads to the provision of a concrete basis for tailoring and implementing mental health intervention policies to cope with challenges efficiently and effectively.

\section{Materials and Methods}

\section{Study setting and population}

An anonymous, internet-based, crosssectional survey was conducted from March to April 2020 at the time of movement restriction. The study population was Filipinos. Inclusion criteria were as follows: At least 18 years of age and naturally born Filipino. The only exclusion criterion was residence in the Philippines of less than 1 week when the COVID19 pandemic announcement was issued by the WHO. The structured online questionnaires were conveniently distributed through email and some social media platforms throughout the Philippines. The respondents' social media accounts were identified and linked with all coresearchers and colleagues.

\section{Instruments}

Data were collected through a structured online questionnaire. The questionnaire has two parts: Sociodemographic data (stage, gender, age, education, marital status, and comorbidities); COVID19 Peritraumatic Distress Index (CPDI), which was developed by Qiu et al. [9]. COVID-19 CPDI is a selfreported questionnaire with 24 questions based on a Likert scale (never, occasionally, sometimes, often, and always) for anxiety, depression, specific phobias, cognitive change, avoidance, compulsive behavior, physical symptoms, and loss of social functioning in the past week. The questionnaire incorporated relevant diagnostic guidelines for specific phobias and stress disorders specified in the International Classification of Diseases (11 ${ }^{\text {th }}$ Ed.) and expert opinions from psychiatrists and psychologists. The total score ranges from 0 to 100; a score between 28 and 51 indicates mild-to-moderate distress; A score of $\geq 52$ stands for severe distress [9]. After translating CPDI into Filipino, linguistic and content validation was conducted by the group of expert panel members, that is, psychiatrists, clinical psychologists, and public health professionals. A pilot study of 50 participants was used to assess the validity and internal consistency of the instrument. The Cronbach's alpha of 0.92 indicated that the questionnaire was an excellent internal consistency.

\section{Data collection}

Our study was an online survey with completely voluntary and anonymous participation. After obtaining the participants' consent, they could respond to the questions only once through a single account by setting the feature to prevent more than 1 response from the same history. The participants were asked to give a response based on their previous 1-week experience.

\section{Statistical analysis}

Data were analyzed using Stata 15.1. Descriptive statistics (using count and proportion) were employed to summarize the sociodemographic profile of survey respondents. Besides, the prevalence of the three-level CPDI was described for all respondents by sociodemographic profile. Logistic regression analysis was performed to identify significant predictors of

Table 1: Sociodemographic profile of the Filipino respondents ( $n=407)$

\begin{tabular}{lll}
\hline Variables & $\mathrm{n}$ & $\%$ \\
\hline Age & & \\
$\quad<30$ years & 200 & 49.1 \\
30-45 years & 152 & 37.3 \\
$>45$ years & 55 & 13.5 \\
Gender & & \\
$\quad$ Male & 176 & 43.2 \\
$\quad$ Female & 231 & 56.8 \\
Religion & & \\
$\quad$ Non-Christian & 33 & 8.1 \\
$\quad$ Christianity & 374 & 91.9 \\
Education & & \\
Primary & 15 & 3.7 \\
Secondary & 43 & 10.6 \\
$\quad$ Tertiary & 349 & 85.7 \\
Employment status & & \\
$\quad$ Students & 79 & 19.4 \\
Unemployed & 54 & 13.3 \\
Employed & 274 & 67.3 \\
Monthly family income & & \\
$\quad<$ Php 19,040 & 151 & 37.1 \\
$\quad$ Php 19,041-66,640 & 211 & 88.9 \\
$\quad>$ Php 66,641 & 45 & 11.1 \\
Region & & \\
$\quad$ Luzon & 130 & 31.9 \\
Visayas & 120 & 29.5 \\
Mindanao & 157 & 38.6 \\
Occupation & & \\
$\quad$ Non-health care & 358 & 88.0 \\
Health care & 49 & 12.0 \\
\hline
\end{tabular}


distress on a two-level scale with model building through backward elimination. This downgrade from a three-level to two-level scale was due to the violation of the proportional odds assumption when ordinal logistic regression was used to identify significant predictors of distress on a three-level scale. Binomial logistic regression was preferred to multinomial logistic regression for the ease of interpretation.

\section{Results}

There were 407 Filipino survey participants with an average age of 32.0 years; almost half of them aged below 30 years (49.1\%). Most respondents were female $(56.8 \%)$, Christian (91.9\%), degree holders $(85.7 \%)$, non-health care workers $(88.0 \%)$, and employed $(67.3 \%)$ with monthly incomes within Php 19,041-Php 66,640 (88.9\%). The majority of the respondents were living in Mindanao (38.6\%), the South Philippines (Table 1).

Most of the respondents did not feel distressed about COVID-19 (52.1\%), whereas 39.5\% and $8.4 \%$ experienced mild-to-moderate and severe distress, respectively (Figure 1). Table 2 summarizes the prevalence of distress severity based on socioeconomic and demographic characteristics among Filipino respondents.

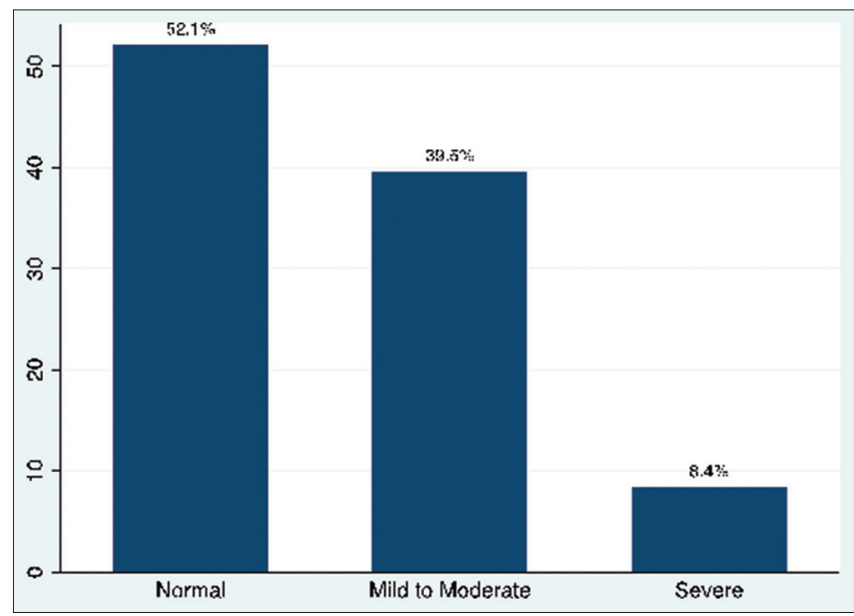

Figure 1: Prevalence of psychological distress due to COVID-19 among Filipino respondents $(n=407)$

The key factors involved in distress among Filipino respondents due to COVID-19 included religion, education, and the region of residence (Table 3 ). Higher religion and faithfulness levels led to a decrease in the odds of being distressed by $50 \%$. On the other hand, the status of completed secondary and tertiary education increased the odds of being distressed by $21 \%$ and $27 \%$, respectively, compared to those who only finished primary education. Finally, respondents living in the Visayas showed greater odds of being distressed by $48 \%$ compared to those living in Luzon. Participants living in
Table 2: Prevalence of CPDI by socioeconomic and demographic characteristics among Filipino respondents $(n=407)$

\begin{tabular}{|c|c|c|c|}
\hline Variables & $\begin{array}{l}\text { Normal or no } \\
\text { distress n (\%) }\end{array}$ & $\begin{array}{l}\text { Mild-to-moderate } \\
\text { distress n }(\%)\end{array}$ & $\begin{array}{l}\text { Severe distress } \\
\mathrm{n}(\%)\end{array}$ \\
\hline \multicolumn{4}{|l|}{ Age } \\
\hline$<30$ years & $104(52.0)$ & $83(41.5)$ & $13(6.5)$ \\
\hline $30-45$ years & $80(52.6)$ & $65(42.8)$ & $7(4.6)$ \\
\hline$>45$ years & 28 (50.9) & $13(23.6)$ & $14(25.5)$ \\
\hline \multicolumn{4}{|l|}{ Sex } \\
\hline Male & $80(45.5)$ & $84(47.7)$ & $12(6.8)$ \\
\hline Female & $132(57.2)$ & 77 (33.3) & $22(9.5)$ \\
\hline \multicolumn{4}{|l|}{ Religion } \\
\hline Non-Christian & $12(36.4)$ & $16(48.5)$ & $5(15.1)$ \\
\hline Christianity & $200(53.4)$ & $145(38.8)$ & $29(7.8)$ \\
\hline \multicolumn{4}{|l|}{ Education } \\
\hline Primary & $5(60.0)$ & $5(13.3)$ & $5(26.7)$ \\
\hline Secondary & $14(32.6)$ & $21(48.8)$ & $8(18.6)$ \\
\hline Tertiary & $189(54.2)$ & $138(39.5)$ & $22(6.3)$ \\
\hline \multicolumn{4}{|l|}{ Employment status } \\
\hline Students & $43(54.4)$ & $28(35.4)$ & $8(10.2)$ \\
\hline Unemployed & $29(53.7)$ & $15(27.8)$ & $10(18.5)$ \\
\hline Employed & $140(51.1)$ & $118(43.1)$ & $16(5.8)$ \\
\hline \multicolumn{4}{|l|}{ Monthly family income } \\
\hline$<$ PHP 19,040 & $82(55.0)$ & 47 (31.6) & $20(13.4)$ \\
\hline Php 19,041-66,640 & $110(51.7)$ & $94(44.1)$ & $9(4.2)$ \\
\hline >Php 66,640 & $20(44.4)$ & $20(44.4)$ & $5(11.2)$ \\
\hline \multicolumn{4}{|l|}{ Region } \\
\hline Luzon & $84(64.6)$ & $38(29.2)$ & $8(6.2)$ \\
\hline Visayas & $28(23.3)$ & $77(64.2)$ & $15(12.5)$ \\
\hline Mindanao & $100(63.7)$ & $46(29.3)$ & $11(7.0)$ \\
\hline \multicolumn{4}{|l|}{ Occupation } \\
\hline Non-health care & $184(51.4)$ & $144(40.2)$ & $30(8.4)$ \\
\hline Health care & $28(57.1)$ & $17(34.7)$ & $4(8.2)$ \\
\hline
\end{tabular}

Mindanao indicated lower odds of being distressed by $14 \%$ compared to those living in Luzon.

\section{Discussion}

Although the majority of Filipino respondents did not experience distress induced by the current situation of the COVID-19 pandemic, several participants showed mild-to-moderate and severe distress, which may be due to a lot of factors. Among the different socioeconomic and demographic factors investigated in this study, religion, education, and region of residence were recognized as the significant predictors of distress due to COVID-19.

Religious participants were less likely to be distressed due to their strong faith in God. Most researches have indicated that a strong faith correlates with diminished depression [11], [12], [13], anxiety [14], and suicidal ideation [15], [16] as well as elevated selfesteem and overall well-being. Research has indicated that during a health crisis, many individuals turn to their religion for emotional comfort, strength, and hope. Spiritual beliefs and practices can provide a sense of meaning and purpose when facing negative health circumstances largely beyond one's control [17], [18]. The majority of the Philippines' population is Christian (90\%), with $80 \%$ Roman Catholic and approximately $5 \%$ are Muslims [19].

The participants with at least the secondary level of education showed increased odds of distress compared to those with a lower educational level. This might be because people with higher educational 
Table 3: Predictors of psychological distress for COVID-19 among Filipino respondents $(n=407)$

\begin{tabular}{|c|c|c|c|c|c|c|c|c|}
\hline \multirow[t]{3}{*}{ Factors } & \multicolumn{4}{|c|}{ Univariable analysis } & \multicolumn{3}{|c|}{ Multivariable analysis } & \multirow[t]{3}{*}{$\mathrm{p}$-value } \\
\hline & \multirow[t]{2}{*}{ OR } & \multicolumn{2}{|l|}{$95 \% \mathrm{Cl}$} & \multirow[t]{2}{*}{$p$-value } & \multirow[t]{2}{*}{ Adj. OR } & \multicolumn{2}{|c|}{$95 \% \mathrm{Cl}$} & \\
\hline & & Lower & Upper & & & Lower & Upper & \\
\hline \multicolumn{9}{|l|}{ Age } \\
\hline$<30$ years & reference & & & & & & & \\
\hline $30-45$ years & 0.98 & 0.64 & 1.49 & 0.906 & & & & \\
\hline$>45$ years & 1.04 & 0.58 & 1.9 & 0.886 & & & & \\
\hline \multicolumn{9}{|l|}{ Sex } \\
\hline Male & Reference & & & & & & & \\
\hline Female & 0.63 & 0.42 & 0.93 & 0.020 & & & & \\
\hline \multicolumn{9}{|l|}{ Religion } \\
\hline Non-Christian & Reference & & & & & & & \\
\hline Christian & 0.5 & 0.24 & 1.04 & 0.063 & 0.38 & 0.17 & 0.83 & 0.016 \\
\hline \multicolumn{9}{|l|}{ Education } \\
\hline Primary & Reference & & & & & & & \\
\hline Secondary & 3.11 & 0.92 & 10.46 & 0.067 & 3.17 & 0.85 & 11.78 & 0.085 \\
\hline Tertiary & 1.27 & 0.44 & 3.64 & 0.657 & 1.21 & 0.38 & 3.82 & 0.742 \\
\hline \multicolumn{9}{|l|}{ Employment status } \\
\hline Students & Reference & & & & & & & \\
\hline Unemployed & 1.03 & 0.51 & 2.06 & 0.934 & & & & \\
\hline Employed & 1.14 & 0.69 & 1.89 & 0.601 & & & & \\
\hline \multicolumn{9}{|l|}{ Monthly family income } \\
\hline <Php 19,040 & Reference & & & & & & & \\
\hline Php $19,041-66,640$ & 1.15 & 0.75 & 1.74 & 0.525 & & & & \\
\hline >Php 66,640 & 1.53 & 0.78 & 2.99 & 0.214 & & & & \\
\hline \multicolumn{9}{|l|}{ Region } \\
\hline Luzon & Reference & & & & & & & \\
\hline Visayas & 6 & 3.44 & 10.45 & $<0.001$ & 5.48 & 3.12 & 9.62 & $<0.001$ \\
\hline Mindanao & 1.04 & 0.64 & 1.69 & 0.871 & 0.86 & 0.52 & 1.43 & 0.559 \\
\hline \multicolumn{9}{|l|}{ Occupation } \\
\hline Non-health care & Reference & & & & & & & \\
\hline Health care & 0.79 & 0.43 & 1.45 & 0.451 & & & & \\
\hline
\end{tabular}

attainment might be capable of comprehending the situation that they were experiencing in the pandemic. Furthermore, higher educational attainment is strongly associated with better mental health [20]. As further, higher levels of education are thought to generate additional economic resources, fewer chronic stressors, healthier lifestyles, more social support, and, ultimately, better mental health [21].

The Philippines is an archipelago of 7641 islands with three major islands: Luzon, Visayas, and Mindanao. Those living in the Visayas have shown greater odds of distress compared to those living in Luzon, which may be explained by relatively high fatality rate of COVID-19 (2.2\%) in Central Visayas [22]. A paper in Iran [23] highlighted the role of unpredictability, uncertainty, seriousness of the disease, misinformation, and social isolation in stress and mental morbidity. Moreover, the welfare provision role of local to national government necessarily contributes to overcoming the COVID-19 pandemic [24]. Besides, Shigemura et al. [25] emphasized the economic impact of COVID19 and its effects on well-being, as well as the possible high levels of fear and panic-related defensive behaviors such as hoarding and stockpiling of resources in the general population. It also identified populations at higher risk of adverse mental health outcomes, that is, patients with COVID-19 and their families, individuals with existing physical or psychiatric morbidity, and health care workers.

\section{Limitations of the study}

Although the participants were recruited from different regions of the Philippines, the respondents in this quantitative sample did not represent their regions of residence. Therefore, readers should be mindful that the findings of this study cannot be generalized to the entire archipelagic regions in the Philippines. Indicators used in the study are limited only to the factors associated with psychological distress during the COVID-19 pandemic crisis through the CPDI questionnaire. Future studies can employ qualitative methods to extend the current study.

\section{Conclusions}

This study aimed to examine factors associated with psychological distress among Filipinos during COVID-19 pandemic. The results revealed that demonstrated that more than half $(52.1 \%)$ of Filipino respondents did not suffer psychological distress due to the COVID-19 pandemic. Among affected participants, $39.5 \%$ had moderate distress, and only $8.4 \%$ experienced severe distress. Having a strong faith and living in Mindanao led to lower odds of being distressed. Filipinos with higher education levels and those living in the Visayas showed higher odds of being distressed. Relevant mental health intervention policies must be directed to these groups to decrease the current mental health burden in Filipino society.

\section{Acknowledgments}

The authors wish to thank Malou Rodriguez for translating the questionnaire to Filipino. Furthermore, we are grateful to Prof. Yifeng Xu, Jianyin Qiu, and their 
team from Shanghai Mental Health Center, Shanghai Jiaotong University School of Medicine, Shanghai, China, for sharing the CPDI questionnaire.

\section{Authors' Contributions}

RRM conceived and designed the study. RRM and EMF performed validation and reliability of the questionnaire. RRM, EQV, EMF, and AMB collected the data. EQV conducted the statistical analysis and interpretation of the findings. RRM, EQV, EMF, and AMB wrote the final manuscript. All authors read and approved the final version of this manuscript.

\section{References}

1. Huang C, Wang Y, Li X, Ren L, Zhao J, Hu Y, et al. Clinical features of patients infected with 2019 novel coronavirus in Wuhan, China. Lancet. 2020;395(10223):497-506. https://doi. org/10.1016/s0140-6736(20)30183-5

PMid:31986264

2. World Health Organization. Coronavirus Disease 2019 (COVID19) Situation Report. Geneva: World Health Organization; 2020.

3. Rubin GJ, Wessely S. The psychological effects of quarantining a city. BMJ. 2020;368:m313. https://doi.org/10.1136/bmj.m313 PMid:31992552

4. Qiu RT, Park J, Li S, Song H. Social costs of tourism during the COVID-19 pandemic. Ann Tour Res. 2020;84:102994. https:// doi.org/10.1016/j.annals.2020.102994

PMid:32834228

5. Jakovljevic M, Bjedov S, Jaksic N, Jakovljevic I. COVID19 pandemia and public and global mental health from the perspective of global health security. Psychiatr Danub. 2020;32(1):6-14. https://doi.org/10.24869/psyd.2020.6 PMid:32303023

6. Rajkumar RP. COVID-19 and mental health: A review of the existing literature. Asian J Psychiatr. 2020;52:102066. https:// doi.org/10.1016/j.ajp.2020.102066

PMid:32302935

7. Khosravi M. Perceived risk of COVID-19 pandemic: The role of public worry and trust. Electron J Gen Med. 2020;17(4):em203. https://doi.org/10.29333/ejgm/7856

8. Taylor S. The Psychology of Pandemics: Preparing for the Next Global Outbreak of Infectious Disease. Newcastle Upon Tyne: Cambridge Scholars Publishing; 2019. https://doi.org/10.20879/ acr.2020.17.2.98

9. Qiu J, Shen B, Zhao M, Wang Z, Xie B, Xu Y. A nationwide survey of psychological distress among Chinese people in the COVID-19 epidemic: Implications and policy recommendations. Gen Psychiatr. 2020;33(2):e100213. https://doi.org/10.1136/ gpsych-2020-100213

PMid:32215365

10. Khosravi M. Neuroticism as a marker of vulnerability to
COVID-19 infection. Psychiatry Investig. 2020;17(7):710-1. https://doi.org/10.30773/pi.2020.0199

PMid:32654438

11. Dein S. Religious doubts: Implications for psychopathology and psychotherapy. Bull Menninger Clin. 2013;77(3):201-21. https:// doi.org/10.1521/bumc.2013.77.3.201 PMid:24020607

12. Payman $V$, Ryburn $B$. Religiousness and recovery from inpatient geriatric depression: Findings from the PEJAMA study. Aust N Z J Psychiatry. 2010;44(6):560-7.

PMid:20482415

13. Wachholtz AB, Pargament KI. Migraines and meditation: Does spirituality matter? J Behav Med. 2008;31(4):351-66. https://doi. org/10.1007/s10865-008-9159-2

PMid:18551362

14. Walker D, Leach J. Anxiety: Etiology, treatment, and Christian perspectives. J Christ Nurs. 2014;31(2):84-91.

PMid:24693610

15. Hilton SC, Fellingham GW, Lyon JL. Suicide rates and religious commitment in young adult males in Utah. Am J Epidemiol. 2002;155(5):413-9. https://doi.org/10.1093/aje/155.5.413 PMid:11867352

16. Rasic DT, Belik SL, Elias B, Katz LY, Enns M, Sareen J, et al. Spirituality, religion and suicidal behavior in a nationally representative sample. J Affect Disord. 2009;114(1-3):32-40. https://doi.org/10.1016/j.jad.2008.08.007 PMid:18799219

17. Richardson P. Spirituality, religion and palliative care. Ann Palliat Med. 2014;3(3):150-9. https://doi.org/10.3978/j. issn.2224-5820.2014.07.05 PMid:25841692

18. Zhang B, Nilsson ME, Prigerson HG. Factors important to patients' quality of life at the end of life. Arch Intern Med. 2012;172(15):1133-42. https://doi.org/10.1001/ archinternmed.2012.2364

PMid:22777380

19. Lally J, Samaniego RM, Tully J. Mental health legislation in the Philippines: Philippine Mental Health Act. BJPsych Int. 2019;16(3):65-7. https://doi.org/10.1192/bji.2018.33 PMid:31385981

20. Bierman A. In: Aneshensel CS, Phelan JC, editors. Handbook of the Sociology of Mental Health. New York: Kluwer Academic/ Plenum Publishers; 1999.

21. Mirowsky J, Ross CE. Education, Social Status, and Health. Piscataway, NJ: Transaction Publishers; 2003.

22. Doh Central Visayas Center for Health Development, COVID-19 Updates; 2020. Available from: http://www.ro7.doh.gov.ph. [Last accessed on 2020 Jun 07].

23. Zandifar A, Badrfam R. Iranian mental health during the COVID19 epidemic. Asian J Psychiatr. 2020;51:101990. https://doi. org/10.1016/j.ajp.2020.101990

PMid:32163908

24. Khosravi M. Stress reduction model of COVID-19 pandemic Iran J Psychiatry Behav Sci. 2020;14(2):e103865. https://doi. org/10.5812/ijpbs.103865

25. Shigemura J, Ursano RJ, Morganstein JC, Kurosawa M, Benedek DM. Public responses to the novel 2019 coronavirus (2019-nCoV) in Japan: Mental health consequences and target populations. Psychiatry Clin Neurosci. 2020;74(4):281-2. https:// doi.org/10.1111/pcn.12988

PMid:32034840 